\title{
A Novel Design of Patch Antenna using U-Slot and Defected Ground Structure
}

\author{
Saad Hassan Kiani ${ }^{1}$, Khalid Mahmood ${ }^{2}$, Mehre Munir $^{3}$, Alex James Cole ${ }^{4}$ \\ Member IEEE ${ }^{1,2,3}$ \\ School of Engineering and Digital Arts, University of Kent, Kent, United Kingdom. ${ }^{4}$
}

\begin{abstract}
A novel design of patch antenna is presented with double $U$ slot structure on patch with ground irregularities. As a result tri-band response is achieved with gain reaching 0.785 to $3.75 \mathrm{~dB}$ respectively and directivity of 5.5 to $5.6 \mathrm{dBi}$. Coaxial cable is mounted with patch as medium of power. The antenna has shown minimum mismatch loss with 0 to $5 \%$ with high bandwidth response of 37 to $1200 \mathrm{MHZ}$. The proposed antenna can be used for GSM, W-LAN, GPRS and other radio communication services systems.
\end{abstract}

Keywords-multiband frequencies; directivity; gain; slots; Bandwidth; reflection coefficient

\section{INTRODUCTION}

With rapid advancement in communication technology in modern era, antenna designers and researchers have been focused to new designs and structures. Patch antenna due to its low profile structures has been a prominent point of attention to communication technology. With their use as an array, resulting in powerful signals gain, bandwidth and directivity they have been frequently used for far in space communication and satellite systems. Regarding to reduction of size in patch structures and multiband response, several techniques have been proposed and implemented. Some of them are discussed.

With use of CSRR as defection of patch, size reduction was up to only $17 \%$ in [1] with altered radiation patterns. Use of synthetic magnetic conductors resulted with lowered gain at desired resonant frequencies [2].Using artificial magnetic conductors, nearly $40 \%$ of miniaturization is achieved at expense of efficiency [3]. Introducing incensement in electrical permittivity of a substrate, size reduction can be achieved but at the bandwidth gets worse [4]. Stack configuration with pi-shape fractal patch structure in [5] resulted size reduction with nearly diminishing gain. Hence Metamaterials, Stacked configuration, slotting techniques [6] [7] [8] [9] [10] size reduction and multiband response has been seen as very common topic among designers and researchers. In this paper, a novel design of patch antenna is presented. Two double $U$ slots on patch and with help of ground irregularities, size reduction is achieved with multiband response which will be discussed below.

The antenna is designed in Computer Simulation Technology 2014. This paper is organized as following.

Starting from introduction, follows antenna design terminologies and slot method for size reduction. After result and discussion, Conclusion and Future work to be done is presented.

\section{ANTENNA DESIGN}

The fundamental structure of patch antenna is presented in figure 1 which consists of ground, substrate and radiating patch.

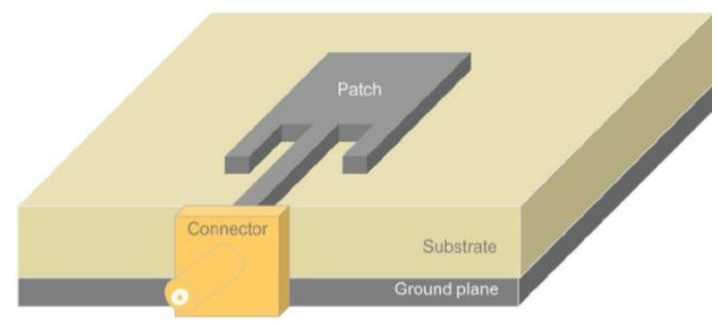

Fig. 1. Fundamental Patch Design

A. Substrate

Substrate plays a very important role in antenna performance parameters. Due to its moisture handling capabilities and commercially availability, FR4 with relative permittivity of 4.3 is selected [11].

B. Width

Antenna width is calculated using equation 1 [11] [12].

$$
W=\frac{c}{2 f_{0} \sqrt{\frac{(\varepsilon r+1)}{2}}}
$$

Where $\mathrm{c}$ is the speed of light in free space. $f_{0}$ is the resonant frequency and $\boldsymbol{\varepsilon} \mathbf{r}$ is the relative substrate permittivity.

C. Length

Patch length is calculated using equation 2 [11] [12].

$$
L=L(e f f)-2 \Delta L
$$

Where

$$
L(e f f)=\frac{c}{2 f_{0} \sqrt{\varepsilon_{(\text {reff })}}}
$$

And

$$
\varepsilon_{(r e f f)}=\frac{\varepsilon r+1}{2}+\frac{\varepsilon r-1}{4}\left(1+\frac{12 h}{W}\right)^{-1 / 2}
$$

Where $\mathrm{h}$ is the height and $\mathrm{W}$ is the width of the patch. After deriving all the basic design parameters, patch antenna resonation at $4.5 \mathrm{GHz}$ is designed. The height of the patch and 
ground is kept $0.787 \mathrm{~mm}$ respectively. Substrate thickness is kept $1.6 \mathrm{~mm}$.

The table 1 below shows dimension of conventional patch antenna.

TABLE I. DimENSIONS OF PATCH ANTENNA

\begin{tabular}{|l|l|}
\hline Parameters & Values in MM \\
\hline Patch Length & 15.35 \\
\hline Patch Width & 20.48 \\
\hline Patch height & 0.787 \\
\hline Ground Length & 27.35 \\
\hline Ground Width & 32.48 \\
\hline Ground Height & 0.787 \\
\hline
\end{tabular}

The table 2 below shows of the U slots introduced in patch and ground plane.

TABLE II. DIMENSIONS OF U SLOTS IN ANTENNA

\begin{tabular}{|l|l|}
\hline Parameters & Value in MM \\
\hline $\begin{array}{l}\text { Patch upper U slot length and } \\
\text { width }\end{array}$ & 6.0 \\
\hline U slot Thickness & 1.0 \\
\hline $\begin{array}{l}\text { Patch lower U slot length and } \\
\text { width }\end{array}$ & 12.0 \\
\hline Patch lower U slot width & 6.0 \\
\hline Ground U slot length and width & 24 \\
\hline
\end{tabular}

The antenna after introducing slots in its structure showed multiband response with good gain, directivity and radiation patterns. The overall antenna design is shown in figure 2. The (a) part represents patch and (b) represents ground plane.
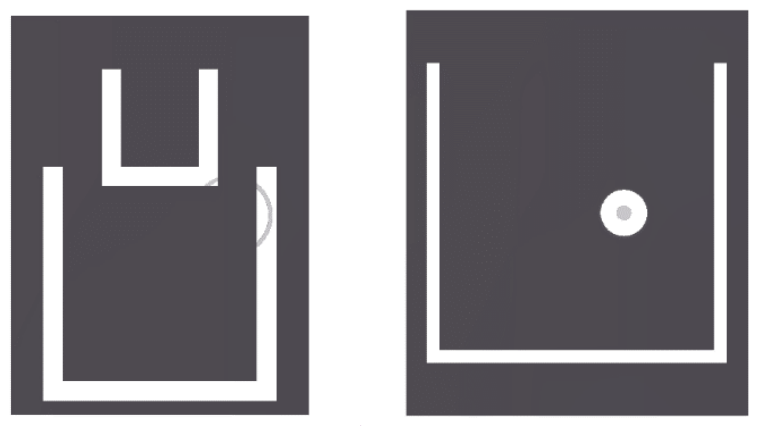

Fig. 2. (a) Frontal view of patch (b) Frontal view of Ground plane
We have used SMA connector for feeding antenna configuration as it is simply executed to $50 \mathrm{ohms}$ of input resistance at required place in patch.

\section{RESUlTS AND DiscUSSIONS}

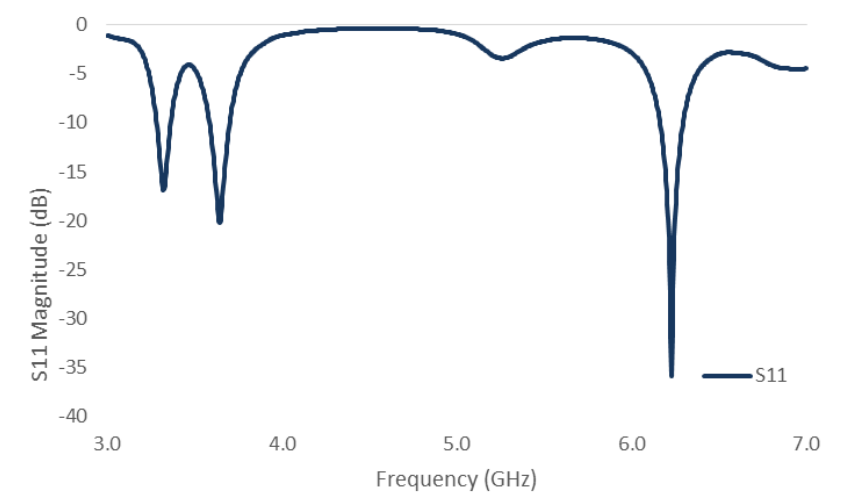

Fig. 3. Return loss graph of antenna

Figure 3 shows the return loss graph of proposed antenna. Resonation at 3 different frequencies, our proposed structure shows multiband response. The results are shown in table 3.

TABLE III. RETURN LOSS VALUES

\begin{tabular}{|l|l|}
\hline Frequencies (GHz) & Return Loss \\
\hline 3.32 & $-19.50 \mathrm{~dB}$ \\
\hline 3.64 & $-19.40 \mathrm{~dB}$ \\
\hline 6.23 & $-35.79 \mathrm{~dB}$ \\
\hline
\end{tabular}

As compared to the conventional antenna for $4.5 \mathrm{GHz}$, the fundamental frequency of our proposed structure shifts down to $3.23 \mathrm{GHz}$. Now the conventional antenna for $3.32 \mathrm{GHz}$ of frequency would require dimensions of 22.18 x28.80 $=638.74 \mathrm{~mm}^{2}$ while in our case it's just $15.35 \mathrm{x} 20.48$ $=314.368 \mathrm{~mm}^{2}$. So it shows that size is reduced in our proposed design up to $51 \%$ as our design is operating at $49 \%$ of conventional patch size with multiband response. 
Farfield Gain Abs (Phi=90)

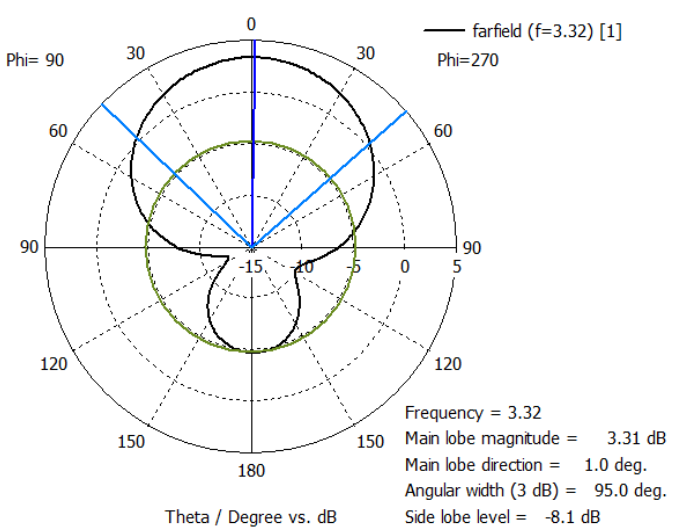

Fig. 4. 3.32GHz $1 \mathrm{D}$ Gain radiation pattern

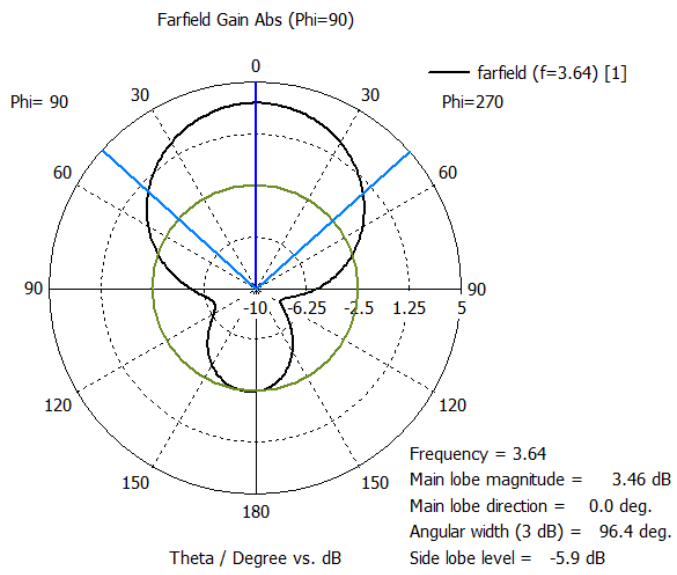

Fig. 5. $3.64 \mathrm{GHz} 1 \mathrm{D}$ gain radiation pattern

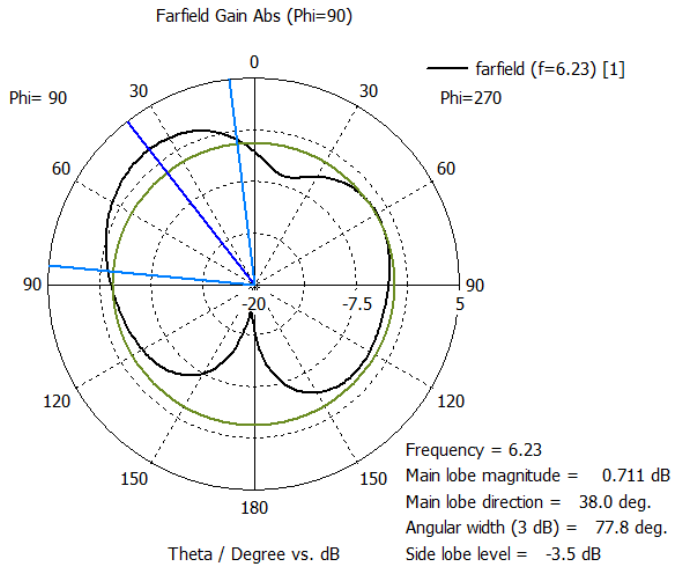

Fig. 6. $6.23 \mathrm{GHz} 1 \mathrm{D}$ gain radiation pattern

The radiation patterns of gain are presented in above and directivity are presented in below figures. In all resonating frequencies, there is minimum back lobe radiations better than [10]. The front lobe, back lobe, angular width and side lobe levels are mentioned in table 4 and 5.

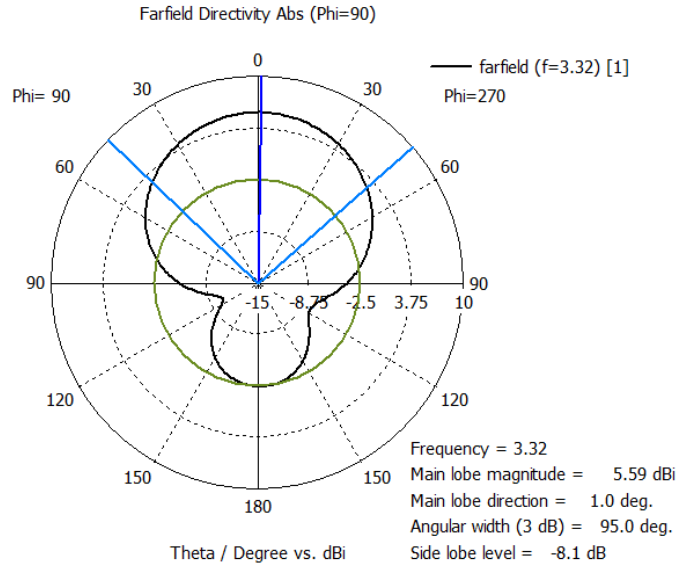

Fig. 7. $3.32 \mathrm{GHz} 1 \mathrm{D}$ radiation pattern of directivity

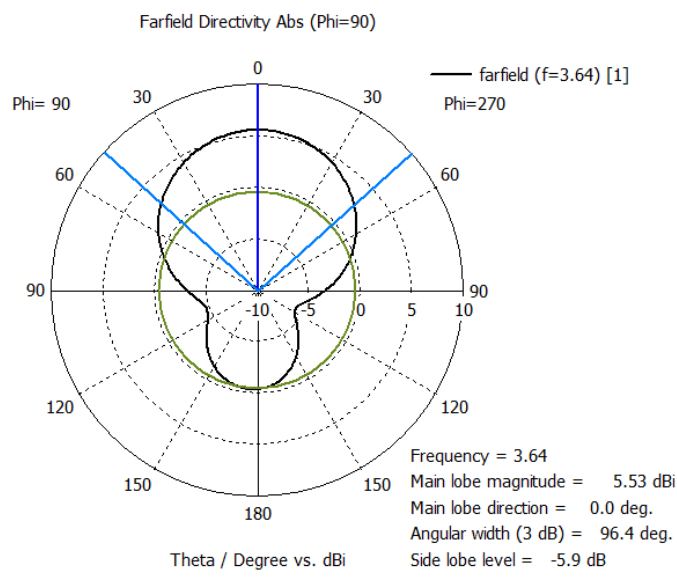

Fig. 8. $3.64 \mathrm{GHz} 1 \mathrm{D}$ radiation pattern of directivity

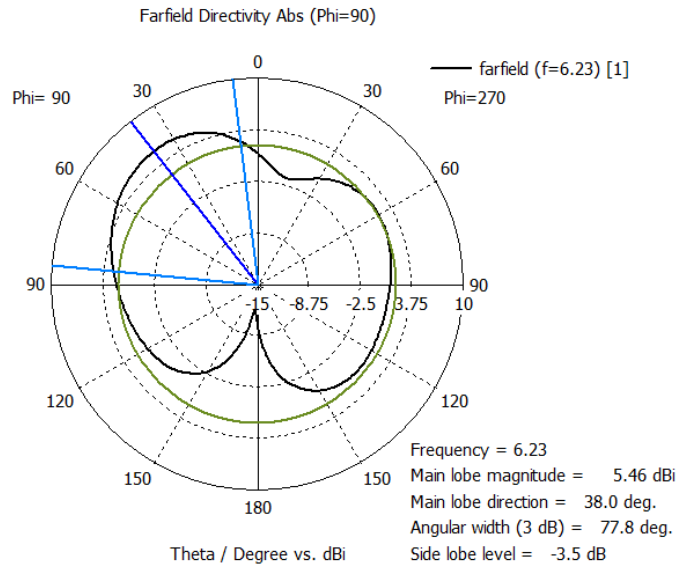

Fig. 9. $6.23 \mathrm{GHz} 1 \mathrm{D}$ radiation pattern of directivity

TABLE IV. GAIN RADIATION PATTERN PARAMETERS

\begin{tabular}{|l|l|l|l|}
\hline $\begin{array}{l}\text { Frequency } \\
(\mathbf{G H z})\end{array}$ & $\begin{array}{l}\text { Main lobe } \\
\text { Direction } \\
\text { (Degrees) }\end{array}$ & $\begin{array}{l}\text { Angular } \\
\text { Width }\end{array}$ & $\begin{array}{l}\text { Side Lobe } \\
\text { Level (dB) }\end{array}$ \\
\hline 3.32 & 1.0 & 95.0 & -8.1 \\
\hline 3.64 & 0.0 & 96.4 & -5.9 \\
\hline 6.23 & 38.0 & 77.8 & -3.5 \\
\hline
\end{tabular}


TABLE V. DIRECTIVITY RADIATION PATTERN PARAMETERS

\begin{tabular}{|l|l|l|l|}
\hline $\begin{array}{l}\text { Frequency } \\
(\mathbf{G H z})\end{array}$ & $\begin{array}{l}\text { Main lobe } \\
\text { Direction } \\
\text { (Degrees) }\end{array}$ & $\begin{array}{l}\text { Angular } \\
\text { Width }\end{array}$ & $\begin{array}{l}\text { Side Lobe } \\
\text { Level (dB) }\end{array}$ \\
\hline 3.32 & 1.0 & 95.0 & -8.1 \\
\hline 3.64 & 0.0 & 96.4 & -5.9 \\
\hline 6.23 & 38.0 & 77.0 & -3.5 \\
\hline
\end{tabular}

From the results mentioned in table 4 and 5 it is cleared that radiation patterns obtained are far better than [9] [10] as antenna is conducting straight form origins. The VSWR ration also tends to be very satisfying in between range of 1 to 1.5 and ensuring no mismatch losses. The gain, directivity, bandwidth and VSWR are presented in table 6.

TABlE VI. ANTENNA PERformance PARAmeters

\begin{tabular}{|l|l|l|l|l|}
\hline $\begin{array}{l}\text { Frequency } \\
(\mathbf{G H z})\end{array}$ & $\begin{array}{l}\text { Gain } \\
(\mathbf{d B})\end{array}$ & $\begin{array}{l}\text { Directivity } \\
(\mathbf{d B i})\end{array}$ & VSWR & $\begin{array}{l}\text { Bandwidth } \\
(\mathbf{M H z})\end{array}$ \\
\hline 3.32 & 3.47 & 5.5 & 1.35 & 112.55 \\
\hline 3.64 & 3.50 & 5.6 & 1.22 & 75.000 \\
\hline 6.23 & 0.75 & 5.5 & 1.03 & 37.244 \\
\hline
\end{tabular}

\section{CONCLUSION}

A novel combination of $U$ slot patch is presented. Our design showed multiband response with size reduction of $51 \%$ also the gain and directivity and other performance parameters have shown satisfied results with nearly zero percent mismatch losses. The proposed antenna can be used for GSM, GPRS, W-LAN and other radio satellite services.

\section{FUTURE WORK}

The design can also be implemented via other contacting schemes and in multiple input multiple output designs with stack configuration technique.

\section{REFERENCES}

[1] Shareef, A. N., \& Shaalan, A. B. Size Reduction of Microstrip Patch Antenna by Using Meta-Fractal Technique.
[2] Rahmadani and A. Munir, "Microstrip patch antenna miniaturization using artificial magnetic conductor," in Telecommunication Systems, Services, and Applications (TSSA), 2011 6th International Conference on, 2011, pp. 219-223.

[3] M. E. Ermutlu, C. R. Simovski, M. K. Karkkainen, P. Ikonen, S. A. Tretyakov and A. A. Sochava, "Miniaturization of patch antennas with new artificial magnetic layers," IWAT 2005. IEEE International Workshop on Antenna Technology: Small Antennas and Novel Metamaterials, 2005., 2005, pp. 87-90.

[4] J. S. Colburn and Y. Rahmat-Samii, "Patch antennas on externally perforated high dielectric constant substrates," IEEE Trans. Antennas Propag., vol. 47, no. 12, pp. 1785-1794, 1999

[5] Munir, M., Altaf, A., \& Hasnain, M. (2015, July). Miniaturization of microstrip fractal H-Shape patch antenna using stack configuration for wireless applications. In Recent Trends in Information Systems (ReTIS), 2015 IEEE 2nd International Conference on Jul 9(pp. 44-48).IEEE

[6] Kiani SH, Qureshi SS, Mahmood K, Mehr-e-Munir, Khan SN. Tri-Band Fractal Patch Antenna for GSM and Satellite Communication Systems. INTERNATIONAL JOURNAL OF ADVANCED COMPUTER SCIENCE AND APPLICATIONS. 2016 Oct 1;7(10):182-6.

[7] Elfergani, I. T. E., Abd-Alhameed, R. A., See, C. H., Sadeghpour, T., \& Jones, S. M. R. (2011, November). Reconfigurable antenna design approach for mobile applications and a technique for harmonics suppression. In Antennas and Propagation Conference (LAPC), 2011 Loughborough (pp. 1-4). IEEE.

[8] Manzoor, Z., and G. Moradi. "Optimization of Impedance Bandwidth of a Stacked Microstrip Patch Antenna with the Shape of Parasitic Patch's Slots." Applied Computational Electromagnetics Society Journal 30.9 (2015)

[9] Kiani SH, Mahmood K, Shafeeq S, Munir M, Khan KM. A Novel Design of Miniaturaized Patch Antenna Using Different Substrates for S-Band and C-Band Applications. International Journal of Advanced Computer Science and Applications (IJACSA). 2016 Jul 1;7(7).

[10] Saad Hassan Kiani, Khalid Mahmood, Umar Farooq Khattak, BurhanUd-Din and Mehre Munir, "U Patch Antenna using Variable Substrates for Wireless Communication Systems" International Journal of Advanced Computer Science and Applications(IJACSA), 7(12), 2016.

[11] Balanis, Constantine A. Antenna theory: analysis and design. John Wiley \& Sons, 2016.

[12] Pozar, David M. "Microwave Engineering 3e." Tramsmission Lines and Waveguides (2005): 143-149. 